\title{
Superior Rectus Muscle
}

National Cancer Institute

\section{Source}

National Cancer Institute. Superior Rectus Muscle. NCI Thesaurus. Code C33694.

One of the extraoculomotor muscles, which arises from a common tendinous ring in the posterior portion of the orbit, inserts on the upper part of the sclera, is innervated by $\mathrm{CN}$ III, and functions to elevate, adduct, and medially rotate the eye. 